\title{
Stabilization of Lateritic Soil Admixed with Maize Husk Ash
}

\author{
${ }^{1}$ Oluremi J. R., ${ }^{2}$ Fagbenro K. O. ${ }^{3}$ Osuolale O. M. and ${ }^{4}$ Olawale, A. M. \\ ${ }^{1,2,3}$ Civil Engineering Department Ladoke Akintola University of Technology Ogbomoso, Oyo State, Nigeria. \\ ${ }^{4}$ Work Department, Osun State University, Osogbo, Osun State, Nigeria. \\ Corresponding Author: kofagbenro@lautech.edu.ng
}

\begin{abstract}
Lateritic soil is one of the major construction materials in road pavement. However, obtaining lateritic soil with sufficient strength is difficult, which may necessitate its improvement by stabilization. Lateritic soil, in this study, was stabilized with upto 12\% Maize Husk Ash (MHA) by weight of soil samples, with a view of improving its geotechnical properties and assessing it as subbase materials.

Classification tests (particle size analysis, specific gravity, Atterbergs limits) and strength index tests (compaction, california bearing ratio $(C B R)$, unconfined compression test (UCS) were performed on both the natural and the MHA-stabilized soil samples.

The grain size analysis shows that the percentage passing No. 200 BS sieve was $47.7 \%$ for the natural lateritic soil and between 50 and $62.1 \%$ for MHA stabilized lateritic soil. The liquid limit, plastic limit and plasticity index are in the range of 61 to $76 \%, 28$ to $53 \%$ and 16 to $37 \%$ respectively. Also, the maximum dry densities increased, while the optimum water content decreased with increase in the MHA content. The CBR value of the lateritic soil increased with MHA content up till $6 \%$ addition of MHA and thereafter decreased, while higher UCS value was obtained up till $3 \%$ and then decreased with increasing content of MHA. The results indicated that the MHA stabilized lateritic soil could only be used as subgrade and fill materials.
\end{abstract}

Keywords: Lateritic soil, Maize husk ash, Stabilization, Compaction and Strength indices

\section{Introduction}

In Nigeria, lateritic soil are commonly use for road construction. Lateritic soils in its natural state generally have low bearing capacity and low strength, due to high content of clay. When lateritic soil contains a large amount of clay materials, its strength and stability cannot be guaranteed under load especially in the presence of moisture (Bell, 1993; Alhassan, 2008).

Lateritic soils are all products of tropical weathering with reddish-brown colour, with or without nodules or concretion and which are found, but not exclusively, below hardened hardpan ferruginous crust (Ola, 1978; Amu et al., 2011). A critical factor in its formation is the alternating or variable moisture cycle associated with grasslands and forests of lowland surfaces in tropical and temperate region (Alhassan, 2008). Precipitation from the water table is now generally considered to be of much greater importance as an effective agent in laterite formation than capillary action. Although, laterite does not develop in arid regions, it is found in them as a relic from earlier, wetter climates. The name 'Laterite' covers a broad range of materials, the origins of which are not well understood. There is still disagreement, especially between pedrologists and soil chemists, over naming and classifying lateritic materials. It has been found that lateritic soils are generally good construction materials and are therefore extensively used in construction (Gidigasu; 1976; Ola, 1978; Gidigasu and Kuma, 1987). In this tropical part of the world, lateritic soils are used as a road making material and they form the sub-grade of most tropical roads, they are used as sub-base for low cost roads and these carry low to medium traffic. Most tropical lateritic soils are composed predominantly of Kaolinite clay mineral with some quartz (Mu'azu, 2008; Oluremi et al., 2016c). In some cases they contain swelling clay mineral type such as vermiculite, hydrated halloysite and montmorillonite. When laterite contains swelling clay mineral type, they are known as problematic laterite, because they are subjected to excessive heaving and usually failed to attain required dry density during road construction.

Technically, soil improvement could either be by modification or stabilization or both. Soil modification is the addition of a modifier (cement, lime etc.) to a soil to change its index properties (Alhassan and Mustapha, 2011), while soil stabilization is the treatment of soils to enable improvement in their strength and durability such that they become totally suitable for construction beyond their original classification. Soil stabilization, which refers to a process whereby the physical and/or chemical properties of a soil are modified in order to suit the purpose for which a soil is meant, has been an old practice by workers that utilize soils in construction (Bello, 2012). Over the 
years, cement and lime have been the two main materials used for stabilizing soil (Eze-Uzomaka and Agbo, 2010; Joel and Agbede, 2011; Oluremi et al., 2012; Joel and Edeh, 2015; Oluremi et al., 2016a; b). However, these materials have rapidly increased in price due to the sharp increase in the cost of energy and high demand for them (Neville, 2000). It has been observed also that many coal combustion by-products have properties that are beneficial in soil stabilization applications. This include: soil drying, enhancement of sub-grade support capacities for pavement and floor slabs, reduction of shrink-swell properties of soils and improvement in aggregate road base construction and asphalt recycling. It has also been shown by Sear (2005) that Portland cement, by the nature of its chemistry, produces large quantities of $\mathrm{CO}_{2}$ for every ton of its final product which contributes to the melting of the ozone layer covering the earth surface. Therefore, replacing proportion of the Portland cement in soil stabilization with material like maize husk ash will reduce the overall environmental impact of the stabilization process. Also, there are instance where lateritic soil may contain a substantial amount of clay minerals that its strength and stability cannot be guaranteed under load, especially in the presence of moisture (Alhassan, 2008; Oluremi et al., 2016b). These types of laterites are also common in many tropical region including Nigeria, where in most cases, sourcing for alternative soil may prove economically unwise but rather to improve the available soil to meet the desired objective (Osinubi, 1999; Mustapha, 2005; Oluremi et al., 2012). Improvement in the strength and durability of lateritic soil has therefore becomes imperative and this has geared up researchers toward using stabilizing materials that can be source locally at a very low cost. Excellent effort have been made for the successful exploitation of the efficient use of various agricultural and industrial by-products (such as natural fibers, maize cob ash, fly ash, rice husk ash, waste wood ash; maize husk ash; foundry waste; silica fume etc.) that have being continuously generated (Osinubi and Medubi, 1997; Medjo and Riskowiski, 2004; Osinubi et al., 2009; 2011; Oluremi et al., 2012; 2017). The re-use of these waste products will help to save our environment from pollution and severe ecological problem.

Maize Husk $(\mathrm{MH})$ which is a by-product of maize processing is either for domestic consumption or industrial uses. Indiscriminate disposal of maize husk due to gross underutilization as well as lack of appropriate technology to recycle them is a major challenge, which results in environmental problem. This study considered the use of maize husk ash (MHA) as a stabilizer for lateritic soil, towards the improvement of its strength and durability.

\section{Materials Collection and Preparation}

Materials used for this work are lateritic soil and maize husk. The maize husk (MH) was burnt to form maize husk ash (MHA).

\section{Lateritic soil}

The soil used for the study is a lateritic soil which was collected at the depth of $300 \mathrm{~mm}$ to the ground surfaces from a borrow pit on Latitude $7.7667^{\circ}$ and Longitude $4.5667^{\circ}$ in Osun State University, Osogbo campus, Osun State, Nigeria under Guinea Savannah Climate. The samples were air dried and slightly pulverized to remove all the lumped soil.

\section{Maize husk ash}

The maize husk used for the production of maize husk ash was obtained from maize sellers at different locations along Okuku, Ikirun road, Osogbo in Osun State.

The husks were sun dried to make them easily combustible and then burnt inside the iron drum at $700{ }^{\circ} \mathrm{C}$ for 90 minutes inside a galvanized drum to prevent contamination with soil materials. The maize husk ash was sieved through sieve No. 200 to obtain a material of fineness similar to cement shown in Figure 1.

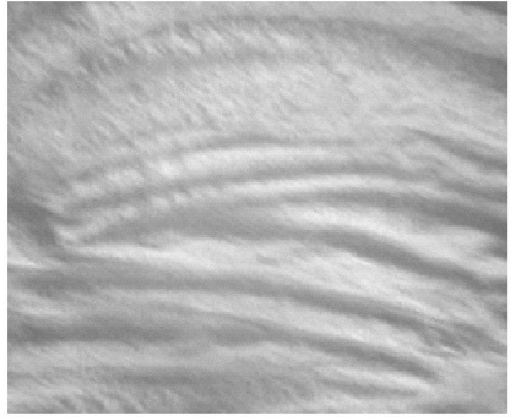

Fig. 1: Appearance of maize husk ash after sieving 


\section{Determination of chemical composition of maize husk ash}

Chemical composition of Maize Husk Ash was carried out at the Centre for Energy Research and Technology, Obafemi Awolowo University, Ile Ife, Osun State using X-ray Flourescence Spectrometer as specified in BS EN 196-2, (1995). The presence and compositions of the following major and minor compounds such as silica $\left(\mathrm{SiO}_{2}\right)$, aluminium oxide $\left(\mathrm{Al}_{2} \mathrm{O}_{3}\right)$, ferric oxide $\left(\mathrm{Fe}_{2} \mathrm{O}_{3}\right)$, calcium oxide $(\mathrm{CaO})$, magnessium oxide $(\mathrm{MgO})$, sulphur trioxide $\left(\mathrm{SO}_{3}\right)$,sodium oxide $\left(\mathrm{Na}_{2} \mathrm{O}\right)$, potassium oxide $\left(\mathrm{K}_{2} \mathrm{O}\right)$ and phosphorus oxide $\left(\mathrm{P}_{2} \mathrm{O}_{5}\right)$ were determined.

\section{Preparation of lateritic soil-maize husk ash mixture}

The stabilized lateritic soil-maize husk ash mixture was prepared by mixing up to $12 \%$ maize husk ash by weight of soil samples with the soil in step concentration of $3 \%$ while $0 \%$ replacement (natural soil) represents the control specimen which is also the unstabilized soil sample.

\section{Geotechnical Laboratory Test}

The following classification (Specific gravity, Particle size analysis, Atterberg limits) and strength indices [Compaction, California bearing ratio (CBR), Unconfined compression test (UCS)] were performed on the stabilized and unstabilized soil samples in accordance to procedures outlined in BS 1377 and 1924 of British Standard Institute (1990), respectively.

\section{Specific gravity test}

The specific gravity of soil samples was determined using density bottle according to BS1377-2 (1990) using $10 \mathrm{~g}$ of soil-MHA mixture in relation to Equation 1. Soil sample was sieved through sieve size $425 \mathrm{~mm}$ and the content which passed through this sieve was used for this test.

$$
\begin{gathered}
\mathrm{SG}=\frac{\mathbf{m}_{2}-\mathbf{m}_{1}}{\left(\mathbf{m}_{4}-\mathbf{m}_{1}\right)-\left(\mathrm{m}_{3}-\mathrm{m}_{2}\right)} \\
\text { Where: } m_{1}=\text { mass of gas jar and ground glass plate (in g); } \\
m_{2}=\text { mass of gas jar, plate and cement (in g); } \\
m_{3}=\text { mass of gas jar, soil and water (in g) and } \\
m_{4}=\text { mass of gas jar, plate and water (ing). }
\end{gathered}
$$

\section{Particle size analysis}

Sieve analysis, also known as gradation test was carried out to classify the soil sample according to their particle size. Predetermined sieve sizes ranging from BS sieve No $4(4.76 \mathrm{~mm})$ to BS sieve No $200(75 \mu \mathrm{m})$ with pan underneath were stacked in descending order. The soil sample was then poured into the top sieve and was covered with a cap. The stacked sieves were placed in the electro-mechanical shaker and carefully shaked for 10 minutes. The mass of soil retained on each of the sieves was determined and the data got was used in calculating the percentage passing each sieve. The percentage passing each sieve was plotted against the sieve sizes.

\section{Atterberg's limit}

The objective of the Atterberg limits test is to obtain consistency behaviour, otherwise known as liquid and plastic limits, of the soil. The liquid limit defines the boundary between plastic and viscous fluid states of the soil, while the plastic limit depicts the boundary between the plastic and the solid state of the soil. Soil sample which passed through sieve No.40 $(425 \mu \mathrm{m})$ was used for the tests in this section.

\section{Liquid limit}

150 gram of air dried soil-MHA was mixed thoroughly with about $20 \%$ of distilled water to obtain homogenous paste. A small sample of soil paste was placed in a liquid limit device and leveled. A groove of about $2 \mathrm{~mm}$ was cut to the base of the cup. The crank of the device was turned and the number of blows $\mathrm{N}$, which caused the groove to nearly close, was counted. A small sample of the soil was taken at the closed point to determine its moisture content. The test was repeated four times for $N \approx(10-20), N \approx(20-30), N \approx(30-40)$ and $N \approx(40-50)$ and the corresponding moisture content was determined. The number of blows was plotted against moisture content on the log-normal graph and the moisture content which corresponds to 25 blows was taken as the liquid limit (LL). This was repeated for all the mixes prepared with $0,3,6,9$ and $12 \%$ MHA.

\section{Plastic limit}

50 gram of soil-MHA mixture was collected and mixed thoroughly with sufficient water to form a stiffen paste which can be kneaded to a small ball of soil. The ball was then rolled in between palm and glass plate until a thread 
of about $3 \mathrm{~mm}$ is formed or the soil crumbled into several pieces. The moisture content of the crumbled soil was determined as plastic limit of the soil. The algebraic difference of both the liquid and plastic limits was taken as the plasticity index of the soil. This procedure was repeated for all the mixes prepared with $0,3,6,9$ and $12 \% \mathrm{MHA}$.

\section{Compaction}

The densification capacity of the soil-MHA mixture was determined using West African Standard (WAS) in order to assess its usability as subbase materials. The compaction test was carried out according to the procedure outlined in BS 1377: Part 2 and BS 1924 of British Standard Institute (1990), in which $3000 \mathrm{~g}$ of each of the soil-MHA mixtures was mixed thoroughly with $5 \%$ water and compacted in 5 layers inside $1000 \mathrm{~cm}^{3}$ mould using $10 \mathrm{blows}$ of $4.5 \mathrm{~kg}$ rammer, dropped from a height of $450 \mathrm{~mm}$ per layer. The data obtained from this test was used in determining the maximum dry density (MDD) and the corresponding optimum moisture content (OMC) for the mix. The procedure was repeated for all the mixes prepared with $0,3,6,9$ and $12 \%$ MHA.

\section{California bearing ratio (CBR)}

With respect to the optimum moisture content of each of the mixes, $5000 \mathrm{~g}$ of soil-MHA mixes were thoroughly mixed with the calculated water and compacted inside a CBR mould relative to the two compactive efforts adopted for use in this work. The unsoaked samples were cured for 7 days before crushing in a compression machine equipped with CBR penetration piston and guarded with $2.25 \mathrm{~kg}$ annular surcharge ring placed on the specimen. For soaked condition, the samples with perforated based and guarded annular ring placed on top of the soil specimen were immersed completely in water for 48 hours in accordance to the condition specified in Nigerian Specification for Road and Highway of the Federal Ministry of Highway and Transportation (1997) and thereafter crushed at penetrations of $0.5,1.0,1.5,2.0,2.5,3.0,3.5,4.0,4.5,5.0,5.5,6.0,6.5,7.0$ and 7.5 under an applied load with a constant rate of penetration $1 \pm 0.2 \mathrm{~mm} / \mathrm{min}$.

\section{Unconfined compressive strength (UCS)}

Lateritic soil-MHA mixture was mixed thoroughly with water content as determined from its OMC. This was put in a $1000 \mathrm{~cm}^{3}$ BS mould and compacted using West African Standard (WAS) compactive efforts. The sample of 23.5 $\mathrm{mm}$ diameter by $47 \mathrm{~mm}$ height was cored and extruded using a locally fabricated corer of size $23.5 \mathrm{~mm}$ by $47 \mathrm{~mm}$ and a jack. The cored samples were cured for seven days and then crushed between the frames of UCS machine. The reading on the strain dial gauge was recorded at constant intervals of loading dial gauge until failure had occurred. This procedure was repeated for all the mix ratios of the additives. The UCSs of the samples were calculated from Equation 2 .

$$
\operatorname{UCS}(\delta)=\operatorname{PCr} \frac{(100-\varepsilon \%) \times 10^{3}}{100 \mathrm{Ao}}
$$

where: $\varepsilon=$ Strain sustained sequent to failure $=\mathrm{x} / \mathrm{L} 0, \mathrm{x}=$ Strain dial reading in $\mathrm{mm}, \mathrm{L} 0=$ Initial length of tested sample $(\mathrm{m}), \mathrm{A} 0=$ Initial cross sectional area of tested sample $\left(\mathrm{m}^{2}\right), \mathrm{P}=$ Load proven ring reading sequent to failure $(\mathrm{kN}), \mathrm{Cr}=$ Compressive stress factor, $\delta=$ Compressive stress at $\operatorname{strain} \varepsilon\left(\mathrm{kN} / \mathrm{m}^{2}\right)$

\section{Results and Discussion}

\section{Chemical composition of MHA}

The results of quantitative analyses of the percentage composition of metal oxides present in the samples of MHA are presented in Table 1.

\begin{tabular}{cc}
\hline Oxide & Percentage Composition \\
\hline $\mathrm{SiO}_{2}$ & 24.53 \\
$\mathrm{Al}_{2} \mathrm{O}_{3}$ & 22.56 \\
$\mathrm{Fe}_{2} \mathrm{O}_{3}$ & 0.58 \\
$\mathrm{CaO}$ & 29.05 \\
$\mathrm{MgO}$ & 7.03 \\
$\mathrm{SO}$ & 1.4 \\
$\mathrm{~K}_{2} \mathrm{O}$ & 16.24 \\
$\mathrm{Na}_{2} \mathrm{O}$ & 19.02 \\
$\mathrm{P}_{2} \mathrm{O}_{5}$ & 2.7 \\
\hline
\end{tabular}


The presence of $29.05 \%$ of $\mathrm{CaO}, 16.24 \%$ of $\mathrm{K}_{2} \mathrm{O}$ and $24.53 \%$ of $\mathrm{SiO}_{2}$ in $\mathrm{MHA}$ shows that MHA is a pozzolanic material that can be used as stabilizing agent. It can be observed that most metal oxides present in both pozzzolan and fly ash are present in MHA and the percentage values of MHA are within the range of fly ash and natural pozzolan. Although its pozzolanicity is verified, however, its reactivity which is a function of hydration modulus (HM) (See Equation 3) is very low (0.61) and for reactions to take place, according to (Kamon and Nontananadh 1991; Muhunthan and Sariosseiri 2008), the hydration modulus (HM) must be greater than 1.7:

$$
\frac{\mathrm{CaO}}{\mathrm{SiO}_{2}+\mathrm{Al}_{2} \mathrm{O}_{3}+\mathrm{Fe}_{2} \mathrm{O}_{3}} \geq 1.7
$$

\section{Specific gravity}

The variation of specific gravity of the soil samples at varying proportion of MHA is shown in Figure 1 . There was reduction in the specific gravity as the MHA content increased in the natural soil. This might be due to the fact that MHA itself, which replaces a large part of the soil samples as the percentage replacement increased, has low specific gravity. Soil sample having 3\% MHA replacement had the closest specific gravity when compared with the control (i.e. soil sample with $0 \% \mathrm{MHA}$ ).

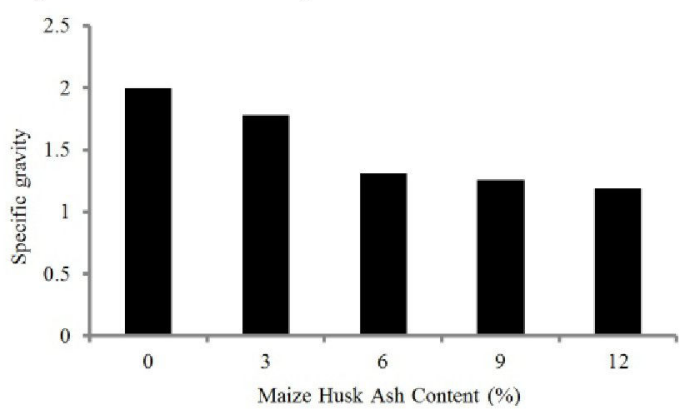

Fig. 1: Relationship between specific gravity and percentage of MHA addition

\section{Sieve analysis of soil}

The grain size analysis as shown in Figure 2 showed that the percentage passing BS sieve No. 200 was $47.7 \%$ for the unstabilized lateritic soil sample but ranged from 50 to $62.1 \%$ for the stabilized soil samples ( 3 to $12 \%$ MHA addition). Lateritic soil sample with $6 \%$ MHA addition had the value of $50 \%$ of soil passing BS sieve No. 200 and this value is the closest to the unstabilized soil sample. These results did not satisfy the specification limits of $35 \%$ or less for road according to the Nigerian Federal Ministry of Highway and Transportation (1997)

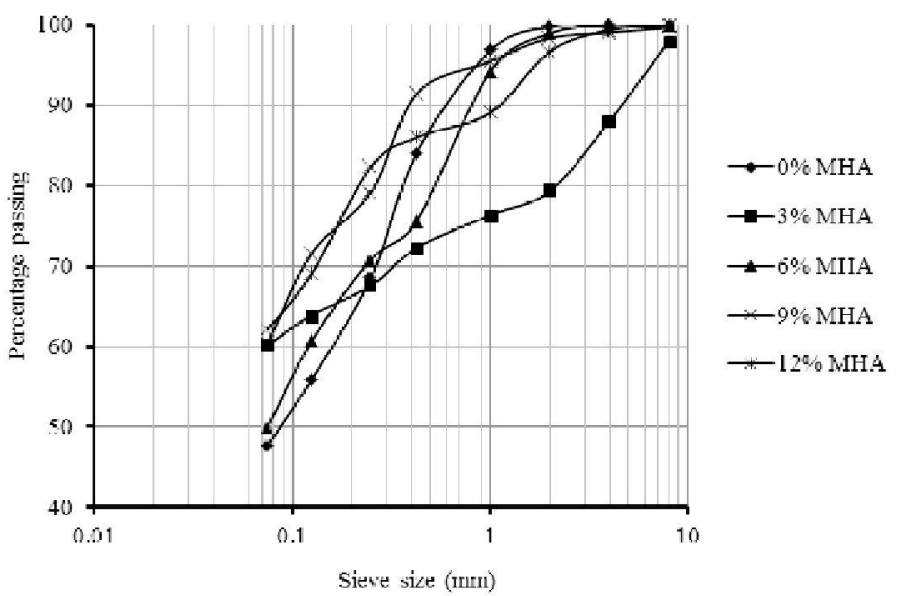

Fig. 2: Particle size distribution of the samples

The uniformity coefficient $\left(C_{\mathrm{u})}\right.$ and the coefficient of gradation $\left(C_{2}\right)$ for both the unstabilized lateritic soil and the stabilized soil samples tend to infinity. The infinity obtained as the value of uniformity coefficient $\left(C_{v}\right)$ made the soil to be described as uniformly graded since the value is greater than 5.0 and the soil has a particle size distribution extending over a limited range, with most particles tending to be about the same size. 


\section{Atterberg limits}

Figure 3 is the variation of the liquid limit and plastic limit with varying MHA content. The liquid limit ranges between $61 \%$ and $76 \%$, plastic limit ranges between 28 and $53 \%$ and plasticity index is between $16 \%$ and $37 \%$. The value of liquid limit decreased from $76 \%$ for natural soil to $61 \%$ with addition of $3 \%$ MHA. There was a further increase in the liquid limit from $61 \%$ for $3 \%$ MHA addition to $70 \%$ for $6 \%$ MHA addition to the natural soil. The liquid limit further declined after $6 \%$ addition of MHA. This suggests that MHA is fit for improving soil with high liquid limit. Venkaramuthyalu et al., (2012) and Ramzi et al., (2001) reported that the reductive change in plasticity index of soil during chemical stabilization could be attributed to the reduction in the thickness of double layer as a result of cation exchange between potassium, calcium and ferric ions.

Nigerian Federal Ministry of Highway and Transportation (1997) recommended liquid limit of $30 \%$ and plasticity index of $12 \%$ maximum for sub-base and base materials. All the studied mixes had more than the recommended maximum value, which therefore renders the soil unsuitable for use as sub-base materials. Results also indicated that the plastic limit decreases as the percentage of MHA increases from 0 to $12 \%$. This shows that MHA can effectively be used to stabilize soil with high clay content or plasticity. The plasticity index also increases as the percentage of MHA, except for soil with $3 \%$ addition which shows a slight decrease from the natural soil. It can also be deduced from Figure 3 that the minimum value of both the liquid limit and plasticity index occurred at $3 \%$ addition of MHA.

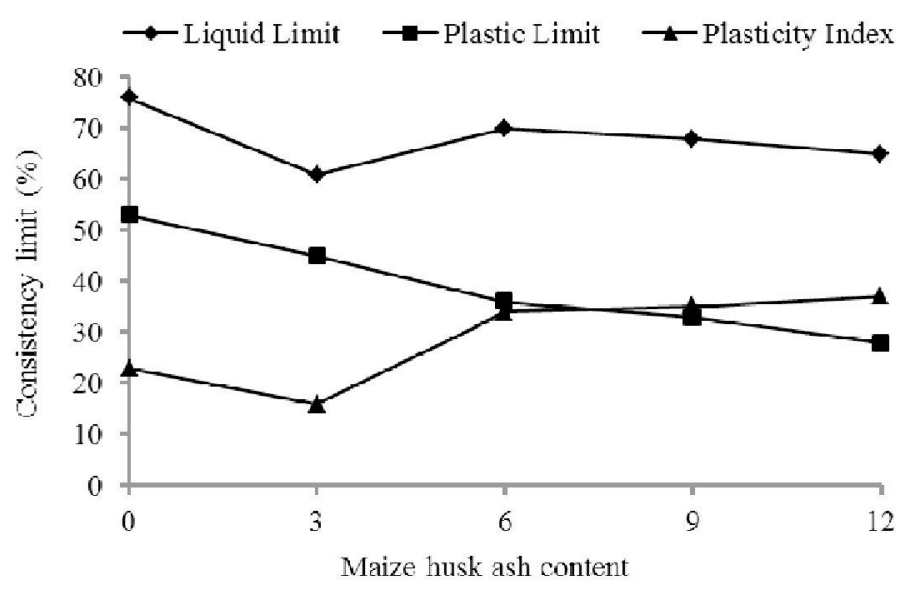

Fig. 3: Relationship between consistency limit and percentage of MHA addition

\section{Compaction characteristics of the soil}

The summary of the results of the West Africa Standard (WAS) compaction showing the variation of MDD with OMC with percentage of MHA addition are shown in Figure 4.

\section{Maximum dry density}

The summaries of compaction characteristics of the samples with the use of WAS compaction are presented in Figure 4. The maximum dry density ranges between 1.90 and $2.11 \mathrm{Mg} / \mathrm{m}^{3}$ and it decreased from 0 up to $6 \% \mathrm{MHA}$ and later increased after the addition of $6 \%$ of MHA but later reduced after $9 \%$ MHA addition. The reduction in maximum dry density shows that the soil is loosely packed and as a result, there will be more voids. The increase in maximum dry density after $9 \%$ addition of MHA could be as a result of the specific gravity of MHA used in the stabilization of the soil. The increase and decrease in maximum dry density might be as a result of binding action and complete reaction of calcium hydroxide on clay soil and MHA respectively.

\section{Optimum moisture content}

The summaries of each sample and corresponding optimum moisture content (OMC) at various percentages of MHA for WAS compaction are shown in Figure 4. The optimum moisture content ranges between 10.0 and $13.5 \%$. Results show that the optimum moisture content decreases from 0 to $3 \%$ and later increase from 11.0 to $12.5 \%$ for 3 to $6 \%$ addition of MHA before it falls to $10.0 \%$ at $9 \%$ addition of MHA.

The increase in OMC was mainly due to the additional water required for wetting the large surface area of the MHA particles or it may be due to the need to add more water for the hydration of MHA. The minimum value 
of MHA occurs at 9\% MHA addition. When optimum moisture content increases, it indicates that the soil is becoming drier and this makes it to have more affinity for water for it to reach its dynamic strength

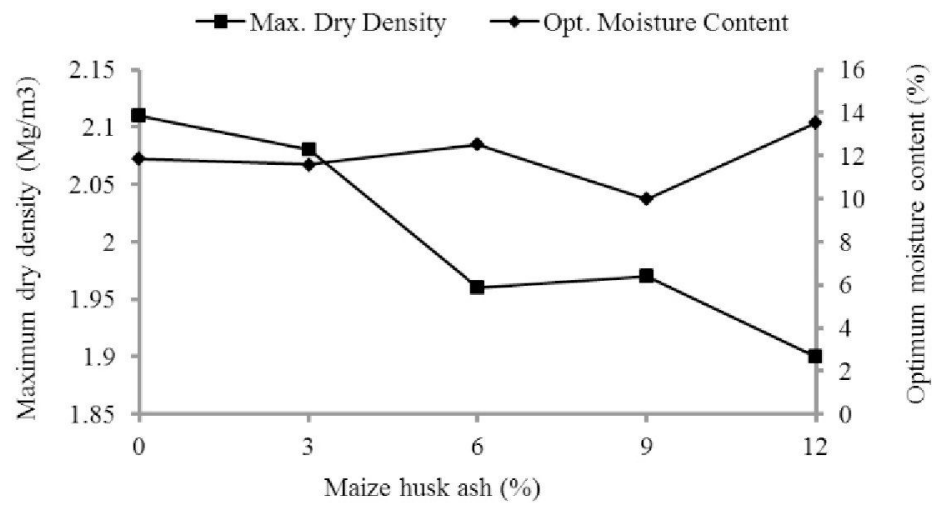

Fig. 4: Variation of maximum dry density and optimum moisture content at WAS compaction with MHA content

\section{Strength characteristics}

The assessment of the load bearing capacity of the modified soil was carried out with CBR and UCS only using WAS compaction method since the modified soil is being assessed as subbase material.

\section{California bearing ratio (CBR)}

Figure 5 shows the variation of the CBR with varying MHA content at both soaked and unsoaked conditions. The values of the california bearing ratio ranges between 18 and $37 \%$ for the unsoaked samples. The value of the CBR for the unstabilized lateritic soil was $33 \%$ and this increased to $37 \%$ as the MHA addition increased to $6 \%$ before it falls to $18 \%$ at $12 \%$ MHA. The maximum unsoaked CBR value of $37 \%$ was obtained at $6 \%$ MHA addition which shows that addition of MHA gradually increases the CBR value of the poor lateritic soil with the maximum value obtained at $6 \%$ addition of MHA. This shows that MHA can be effectively used to improve the CBR value of soil. Although this highest unsoaked CBR met the minimum CBR value of $30 \%$ stipulated for base course material compacted at OMC (BS, 1990), it did not meet the recommended 80\% CBR according to Federal Ministry of Works and Housing (1997) for cement stabilization. Similar results were obtained in Salahudeen and Ochepo, (2015) and Sadeeq et al., (2015).

For soaked condition, the CBR values ranges between 8 and $18 \%$ with maximum value of $18 \%$ obtained for unstabilized lateritic soil. The value of the CBR decreased from 16 to $9 \%$ as MHA content increased from 3 to $6 \%$ and increased from 9 to $13 \%$ as MHA content increased from 6 to $9 \%$ before it finally falls to $8 \%$ at $12 \%$ addition of MHA. Normally, the values of the unsoaked CBR are greater than that of the soaked CBR. This is hinged on the fact that the load bearing capacity of the compacted mixes reduces with increase in the amount of water present in the soil after it has reached its saturation point, which causes the soil particle to shear over one another. The soaked CBR value of $16 \%$ obtained at $3 \%$ addition met the requirement of minimum CBR value of not less than $10 \%$ (Federal Ministry of Works specification for Road Works) for fill materials in flexible pavement.

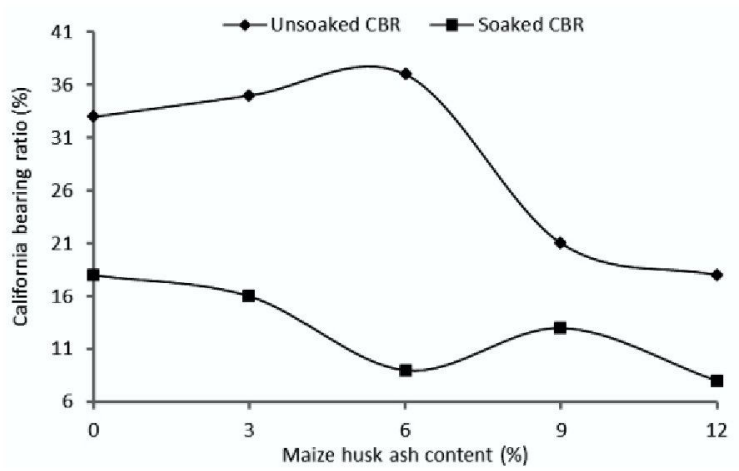

Figure 5: Variation of California bearing ratio with MHA content at both soaked and unsoaked conditions 


\section{Unconfined compressive strength(UCS)}

The relationship between the stress and strain development during the uniaxial compression of each of the MHA stabilized soil (Figure 7a) and the variation of unconfined compressive strength with varying MHA content (Figure $7 \mathrm{~b}$ ) show that the unconfined compressive strength ranges between $87 \mathrm{kN} / \mathrm{m}^{2}$ and $115 \mathrm{kN} / \mathrm{m}^{2}$. The unconfined compressive strength value of the unstabilized lateritic soil was $96 \mathrm{KN} / \mathrm{m}^{2}$ and this value increased to $115 \mathrm{KN} / \mathrm{m}^{2}$ at $3 \%$ addition of MHA. It could be deduced that $3 \%$ addition of MHA to the lateritic soil increased the shear strength of the soil because of the cementing agent ( $\mathrm{Fe}, \mathrm{Mg}, \mathrm{Al}, \mathrm{Ca}$ etc) present in it. The value of unconfined compressive strength increased and decreased as the MHA addition increases from 3 to $1 \%$. The UCS value increased at $3 \%$ MHA addition before it fell to $75 \mathrm{kN} / \mathrm{m}^{2}$ at $6 \%$ addition of MHA and increases to $92 \mathrm{KN} / \mathrm{m}^{2}$ at $9 \%$ MHA addition before it finally falls to $97 \mathrm{KN} / \mathrm{m}^{2}$ at $12 \% \mathrm{MHA}$ addition. However, none of the values for all the additive contents met the $1710 \mathrm{kN} / \mathrm{m}^{2}$ unconfined compressive strength value specified by TRRL (1977) as a criterion for adequate stabilization using Ordinary Portland Cement.

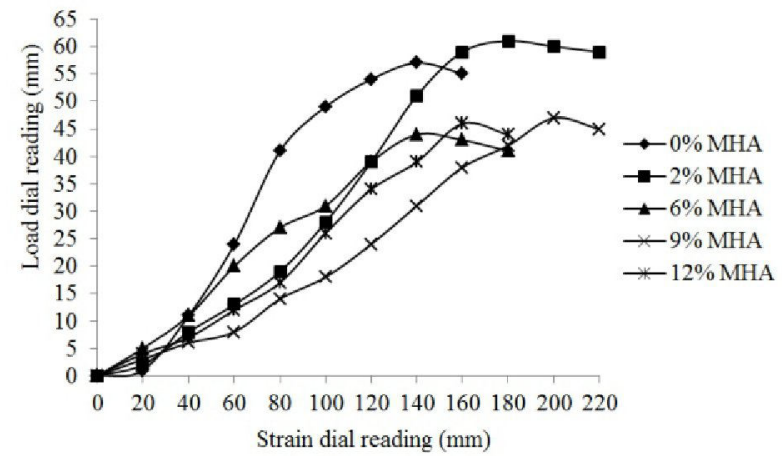

Fig. 7a: Stress-strain relationship for UCS for each MHA content

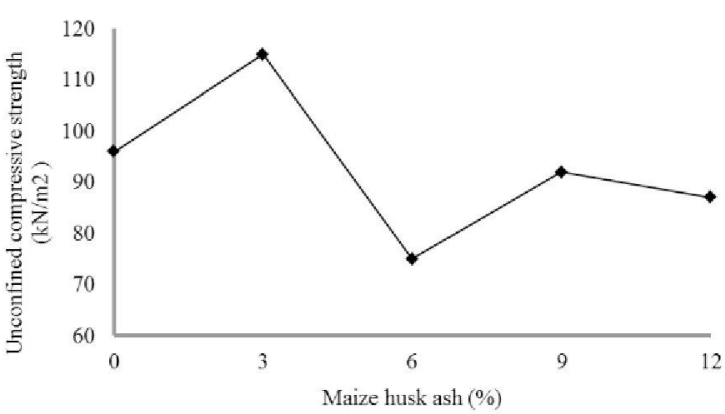

Fig. 7b: Variation of unconfined compressive strength with MHA content

According to Das (2000) unconfined compressive strength is the fundamental determinant of consistency of clayey soil as presented in Table 2 . The soil changed from stiff to medium clay as the percentage of MHA increases from 3 to $12 \%$.

Table 2. Consistency of clayey soil in term of unconfined compressive strength

\begin{tabular}{cc}
\hline Unconlined compressive strenglh & Consistency of the clay \\
$\left(\mathrm{kNN} / \mathrm{m}^{2}\right)$ & \\
\hline $0-25$ & Very soft \\
$25-50$ & Soft \\
$50-100$ & Medium clav \\
$100-200$ & Stiff \\
$>400$ & Hard clay \\
\hline
\end{tabular}

\section{Conclusion}

In this study, the use of MHA as a stabilizing agent for soil was clearly observed. The grain size analysis shows that the percentage passing No. 200 BS sieve was $47.7 \%$ for the unstabilized laterite and between 50.0 and $62.1 \%$ for stabilized laterite soil sample. These values are more than specified limit of $35 \%$ or less according to the Federal Ministry of Works. The Atterberg limits shows that the soil did not fall within the guideline of the Nigerian Federal Ministry of Highways and transportation (1997), that is, the liquid limit is greater than $30 \%$, plastic limit is greater than $12 \%$ and the plasticity index is greater than $8 \%$ as specified by the Nigerian Federal Ministry of Highways and transportation (1997) for use as subbase material. This soil is therefore suitable for use as fill and sub-grade materials only.

Also, the presence of MHA in the soil increased the dry density, which helps to achieve a high degree of compaction at lower moisture content. MHA gradually increased the CBR value of the poor lateritic soil with the maximum value obtained at $6 \%$ addition of MHA. Addition of MHA to the lateritic soil achieved a higher UCS value at $3 \%$ and lower value at higher MHA contents than the natural soil and this indicates that MHA reduces the cohesiveness of the lateritic soil. 
Based on the results discussed above, $6 \% \mathrm{MHA}$ is therefore recommended for use as stabilizer for effective improvement of the geotechnical properties of this lateritic soil.

\section{References}

Alhassan, M and Mustapha, M. (2011). Effect of rice husk ash on cement stabilized laterite. Leonardo Electronic Journal of practice and Technology,11,47-58.

Alhassan, M. (2008). Potentials of Rice Husk Ash for Soil Stabilization. Assumption University Journal of Technology. 11(4): 246-56.

Amu, O. O., Bamisaye, O. F. and Komolafe, I. A. (2011).The suitability and Lime Stabilization requirement of Some Lateritic Soil Samples as Pavement. International Journal of Pure Applied Science and Technology.2(1): 29-46.

Bell, F. G. (1993). Engineering Treatment of Soil Stabilization. E and FNSPON: London, UK

Bello, A. A. (2012). Regression Analysis of Compaction Delay on CBR and UCS of Lime Stabilized Yellowish Brown Lateritic Soil. Electronic Journal of Geotechnical Engineering (EJGE). 17: 127-141.

British Standard Institute (1995) BS EN 196-1: Methods of testing cement - Part 1: Determination of strength British Standards Institution, London, United Kingdom.

British Standards Institute (1990). BS 1377: Methods of testing soil for civil engineering purposes. British Standards Institute, London, United Kingdom.

British Standards Institute (1990). BS1924: Methods of Tests for stabilized Soils. British Standards Institute, London, United Kingdom.

Das, B. M. (2000). Fundamentals of geotechnical engineering. Pacific Grove, CA: Brooks/Cole. p. 593.

Eze-Uzomaka, O.J. and Agbo, D. (2010). Suitability of quarry dust as improvement to cement Stabilizedlaterite for road bases. Electronic Journal of Geotechnical Engineering, 15 (k);1053-1066.

Gidigasu, M. D. (1976). Laterite Soil Engineering: Pedogenesis and Engineering Principle. Elsevier, Amsterdam, the Netherlands.

Gidigasu, M. D. and Kuma, D. O. K. (1987).Engineering Significance of Lateritisation and Profile Development on Soil Mechanics and Foundation Engineering. September, Lagos, Nigeria.1:3-20.

Joel, M and Agbede. I.O. (2011). Mechanical-cement stabilization of laterite for use a flexible pavement material. J.Mater. Civ. Eng, 23 (2):146-152.

Joel, M. and Edeh, J. E. (2015) Comparative Analysis of Cement and Lime Modification of Ikpayongo Laterite for Effective and Economic Stabilization. Journal of Emerging Trends in Engineering and Applied Sciences (JETEAS) 6(1):49-56.

Kamon, M. and Nontananandh, S. (1991). Combining industrial wastes with lime for soil stabilization. Journal of Geotechnical Engineering, 117(1), 1-17.

Medjo, E. and Riskowiski, G. (2004). A Procedure for processing mixtures of soil, cement and sugar cane bagasse. Agricultural Engineering International Journal of Scientific Research and Development. Manuscript BC 990, III: 1-6.

Mu'azu, M. A. (2008). Influence of Compactive Effort on Bagasse Ash with Cement Treated Lateritic Soil.Journal of Sedimentary Petrology. 4(54): 1147-1156.

Muhunthan, B. and Sariosseiri, F. (2008) Interpretation of Geotechnical Properties of Cement Treated Soils. The Federal Highway Administration U.S. Department of Transportation, USA.

Mustapha, M.A. (2005). Effect of Bagasse Ash on Cement Stabilized Laterite. Seminar Paper presented at the Department of Civil Engineering, Ahmadu Bello University, Zaria, Nigeria.

Nigerian Federal Ministry of Highways and Transportation, (1997). General Specification for Roads and Bridges. Federal Highway Department, Lagos. 2: 145-284.

Ola, S.A. (1978). Geotechnical Properties and Behaviour of some Stabilized Nigeria Laterite Soil. Quarterly Journal of Engineering Geology. London. 3:145-160.

Oluremi, J. R, Yohanna, P., Ishola, K, Yisa, G. L, Eberemu, A. O., Ijimdiya, S. T. and Osinubi, K. J. (2017) Plasticity of Lateritic Soil Admixed with Selected Admixtures accepted for publication in Environmental Geotechnics, Institute of Civil Engineering (ICE), United Kingdom, August, 2017,http://dx.doi.org/10.1680/jenge.15.00085

Oluremi, J. R., Osuolale, O. M., Adeoye, T. T. and Akingbade, A. A. (2016b) Strength Development in Lateritic Soil Stabilised with Coconut Shell Ash for Highway Pavement Construction, Innovative Systems Design and Engineering, Vol.7, No.11,pp. 49-56.

Oluremi, J. R., Siddique, R. and Adeboje, E. P. (2016a) Stabilization Potential of Cement Kiln Dust Treated Lateritic Soil. International Journal of Engineering Research in Africa, 23:52-63. http:// doi:10.4028/www.scientific.net/JERA.23.52.

Oluremi, J.R., Adedokun, S. I. and Osuolale, O. M. (2012) Stabilization of Poor Lateritic Soils with Coconut Husk Ash. 
International Journal of Engineering Research \& Technology (IJERT), 1 (8): 1-8. www.jjert.org

Oluremi Eberemu Ijimdiya OsinubiAbsorption and Diffusion Potential of Waste Wood Ash-Treated Lateritic Soil. I. R., A. O.., T. S.and, K. J. (2016c) ASCE Geotechnical Special Publication (GSP) 273: 98-107 http://dx.doi.org/10.1061/9780784480168.011.

Osinubi K.J. (1999). Evaluation of admixture stabilization of Nigeria black cotton soil. Nigeria Society of Engineers Technical Transaction, 34(3): 88-96.

Osinubi, K. J. and Medubi, A. B. (1997). Effect of lime and phosphatic waste admixture on tropical black clay. Proceedings, 4th Regional Conference on Geochemical Engineering, GEOTROPIKA '97, Johor Bahru, 11-12 Nov., Malaysia, pp. 257-272.

Osinubi, K. J., Akinmade, O. B. and Eberemu, A. O. (2009). Stabilization potential of locust bean waste ash on black cotton soil. Journal of Engineering Research, University of Lagos, 4, (2):1-13.

Osinubi, K. J., Oyelakin, M. A. and Eberemu, A. O. (2011). Improvement of black cotton soil with ordinary Portland cement- locust bean waste ash blend. The Electronic Journal of Geotechnical Engineering, 16, (F):785-796.

Ramzi, T., Amer, A., Ali, A., and Hilia A. (2001). Use of cement kiln dust in soil stabilization. EJUQ, 14, 61-76.

Sadeeq, J. A., Ochepo, J., Salahudeen, A. B. and Tijjani, S. T. (2015) Effect of Bagasse Ash on Lime Stabilized Lateritic Soil. Jordan Journal of Civil Engineering, 9 (2): 203-213.

Salahudeen, A. B. and Ochepo, J., (2015). Effect of Bagasse Ash on Some Engineering Properties of Lateritic Soil. Jordan Journal of Civil Engineering, 9 (4): 468-476.

Sear, L. K. A. (2005). Should you be using more PFA. Proceedings of International Conference Cement Combination for Durable Concrete, held at the University of Dundee, Scotland, UK.

TRRL. (1977). A guide to the structural design of bitumen surfaced roads in tropical and sub-tropical countries. Transport and Road Research Laboratory, Road Note31, H. M.S. O., London.

Venkaramuthyalu, P., Ramu, K., and Prasada, R.G.V.R. (2012). Study on performance of chemically stabilized expansive soil. IJAET, 2(1), 139-148. 